\title{
KONSEP PIIL PESENGGIRI DALAM SASTRA LISAN WAWANCAN LAMPUNG SAIBATIN
}

\author{
Jafar Fakhrurozi ${ }^{1}$, Dian Puspita ${ }^{2}$ \\ ${ }^{12}$ Universitas Teknokrat Indonesia \\ Pos-el: jafar.fakhrurozi@teknokrat.ac.id
}

\begin{abstract}
Abstrak
Penelitian ini mengkaji konsep Piil Pesenggiri yang terkandung dalam wawancan masyarakat Lampung Saibatin. Piil Pesenggiri dapat diartikan sebagai keharusan hidup bermoral tinggi, berjiwa besar, tahu diri dan kewajiban. Piil Pesenggiri merupakan falsafah hidup masyarakat adat Lampung yang dijadikan landasan sikap dan perilaku masyarakat dalam kehidupan sehari-hari. Sikap dan perilaku tersebut dapat ditunjukkan melalui sastra lisan. Berdasarkan hal tersebut, penelitian ini berusaha untuk menunjukkan teks wawancan yang mencerminkan konsepsi piil pesenggiri. Penelitian ini menggunakan pendekatan kualitatif dengan metode etnografi. Pengumpulan data dilakukan dengan proses wawancara, dan pendokumentasian tuturan. Selanjutnya data diolah dan dianalisis sehingga dapat terungkap hasil penelitian. Secara umum hasil penelitian menunjukkan adanya empat konsep piil pesenggiri dalam teks wawancan. Hasil penelitian ini dapat dijadikan sebagai upaya pendokumentasian, penyelamatan, dan pelestarian bahasa dan budaya Lampung.

Kata kunci: Piil Pesenggiri, Sastra Lisan, Wawancan, Lampung, Saibatin
\end{abstract}

\begin{abstract}
This study examines the concept of Piil Pesenggiri contained in the wawancan of the Lampung Saibatin community. Piil Pesenggiri can be interpreted as the necessity to live with high morals, to have a big spirit, to know yourself and to have obligations. Piil Pesenggiri is a phil osophy of life for the indigenous people of Lampung which is used as the basis for people's attitudes and behavior in their daily life. These attitudes and behaviors can be shown through oral literature. Based on this, this study seeks to show wawancan texts that reflect the conception of piil pesenggiri. This study uses a qualitative approach with ethnographic methods. The data was collected by means of an interview process and documentation of the speech. Furthermore, the data is processed and analyzed so that it can reveal the results of the research. In general, the results of the study indicate that there are four concepts of piil pesenggiri in wawancan texts. The results of this research can be used as an effort to document, save, and preserve Lampung language and culture.

Key words: Piil Pesenggiri, Oral Literature, Wawancan, Lampung, Saibatin
\end{abstract}




\section{PENDAHULUAN}

Setiap suku bangsa memiliki kekhasan budaya, termasuk masyarakat Lampung. Budaya tersebut dapat ditunjukkan melalui bahasa. Sebagaimana yang dikatakan Koentjaraningrat dalam buku Manusia dan Kebudayaan di Indonesia (2002: 203-204) Kebudayaan mempunyai tujuh unsur universal termasuk di dalamnya bahasa. Bahasa yang digunakan oleh masyarakat dapat merepresentasikan kebudayaan masyarakat tersebut. Oleh karena itu, bahasa termasuk bahasa daerah harus dilestarikan. Bahasa daerah merupakan salah satu unsur pendukung kebudayaan nasional. Hal itu selaras dengan Undang-Undang Dasar 1945 Bab XV, Pasal 32 yang berisi tentang kebudayaan dan Penjelasan Pasal 36 tentang bahasa.

Bagi masyarakat Lampung yang bersifat urban, di mana populasi penduduk asli lebih sedikit dari suku lain, keberadaan bahasa Lampung tentu harus mendapatkan perhatian lebih. Hasil sensus 2010 disebutkan bahwa dari 7.608.405 jumlah penduduk Lampung terdapat 1.381 .866 masyarakat bersuku Lampung atau sekitar 18,3 persen (2011:29-41). Jumlah tersebut diprediksi akan semakin kecil bila dihadapkan perkembangan sosial yang serba modern dan global.

Namun demikian, keberadaan Bahasa Lampung masih dinamis terutama di lingkungan masyarakat adat Lampung. Masyarakat Lampung dibagi menjadi dua kelompok besar yaitu pepadun dan saibatin. Dua adat tersebut dikenal dengan istilah ruwa jurai (dibaca (kh) Khuwa Jurai) yang berarti dua negeri. Kedua kelompok masyarakat adat tersebut memiliki struktur hukum adat yang berbeda. Dalam Ariyani, Farida (2015: 10) disebutkan bahwa masyarakat adat Lampung Saibatin mendiami wilayah adat: Labuhan Maringgai, Pugung, Jabung, Way Jepara, Kalianda, Raja Basa, Teluk Betung, Padang cermin, Cuku Balak, Way Lima, Talang Padang, Kota Agung, Semaka, Suoh, Sekincau, Batu Brak, Belalau, Liwa, Pesisir Krui, Ranau, Martapura, Muara Dua, Kayu Agung, Cikoneng di pantai Banten dan bahkan Merpas di Bengkulu.

Selanjutnya, masyarakat Adat Pepadun/Pedalaman yang terdiri atas Abung Siwo Mego (Unyai, Unyi, Subing, Uban, Anak Tuba, Kunang, Belinyuk, Selagai, Nyerupa. Masyarakat Abung mendiami 7 wilayah adat: Kotabumi, Seputih Timur, Sukada, Labuhan Maringgai, Jabung, Gunung Sugih, dan Terbanggi. Mego Pak Tulang Bawang (Puyang Umpu, Puyang Bulan, Puyang Aji, Puyang Tegamoan). Masyarakat Tulang Bawang mendiami empat wilayah adat: Menggala, Mesuji, Panaragan, dan Wiralaga. Pubian Telu Suku (Minak Patih Tuha atau Suku Manyarakat, 
Konsep Piil Pesenggiri...

Minak Demang lanca atau Suku Tambapupus, Minak Handak Hulu atau Suku Bukujadi). Masyarakat Pubian mendiami delapan wilayah adat: Tanjung Karang, Balau, Bukujadi, Tegineneng, Seputih Barat, Padang Ratu, Gedungtataan, dan Pugung. Sungkay- Waykanan Buay Lima (Pemuka, Bahuga, Semenguk, Baradatu, Baraksakti, yaitu lima keturunan raja Tijang Jungur) (2015:10-11).

Salah satu masyarakat adat yang masih kuat identitas kulturalnya adalah masyarakat adat Lampung Saibatin di daerah Pekon Banding Agung, Talang Padang Kabupaten Tanggamus. Selain masih digunakan sebagai lingua franca, Bahasa Lampung juga masih digunakan dalam upacaraupacara adat. Penggunaan bahasa Lampung dalam ritus budaya masyarakat merupakan salah satu bentuk penjagaan dan pewarisan nilai-nilai budaya yang dianut masyarakat Lampung. Salah tradisi yang masih berkembang dalam ritus hidup masyarakat Saibatin adalah wawancan. Wawancan adalah jenis karya sastra berbentuk syair dengan rima akhir tertentu.

Pada masyarakat Lampung Pepadun wawancan dikenal dengan nama pepaccur. Wawancan disampaikan dalam berbagai peristiwa kehidupan seperti seperti dalam pernikahan, peresmian gedung, pemberian gelar (adok) dll.. Sebagaimana karya sastra atau tradisi lisan lainnya wawancan tentu

memiliki fungsi dan makna yang berguna bagi masyarakat. Dalam wawancan tercermin nilai-nilai budaya masyarakat Lampung.

Dari segi bentuknya wawancan terdiri dari larik-larik serupa puisi/syair/pantun. Sastra lisan di Lampung dari segi bentuknya memang memiliki bentuk serupa pantun. Dalam satu ayat terdiri dari 4 baris dan berima ab-ab. Tetapi ada juga yang identik dengan pantun talibun. Dalam satu ayat terdiri dari enam baris dan berima abc-abc. Namun, pantun dari Lampung tidak memiliki sampiran (pengantar). Setiap baris di pantun semuanya adalah isi. Dalam satu bait, wawancan terdiri dari dari 4 baris dan 6 baris. (Fakhrurozi, 2019: 20).

Dalam wawancan tercermin nilai-nilai budaya masyarakat Lampung. Nilai-nilai yang dimaksud salah satunya adalah Piil Pesenggiri. Menurut Hadikusuma dalam Ariyani, Farida Dkk (2015:15-16) Piil Pesenggiri merupakan nilai dasar atau falsafahnya hidup ulun Lampung. Hal tersebut terlihat dalam pola tingkah laku dan pola pergaulan hidup mereka, baik sesama kelompok mereka maupun terhadap kelompok lain. Makna Piil Pesenggiri juga sering diartikan sebagai tanda atau simbol "harga diri” bagi pribumi Lampung.

Piil Pesenggiri yaitu keharusan hidup bermoral tinggi, berjiwa besar, tahu diri dan kewajiban. Piil ini didampingi oleh empat 
unsur lain yaitu disebut "Juluk Adek, Nemui Nyimah, Nengah Nyappur, dan Sakai Sambayan". Hilma Hadikusuma, S.H. dan Rizani Puspa Wijaya, S.H.mengungkapkan bahwa nilai-nilai dasar yang menjadi pegangan pokok masyarakat Lampung terkandung dalam uraian kalimat berikut ini:

"Tando nou ulun Lappung, wat Pi'il Pesenggiri, yaou balak pi'il ngemik malou ngigau diri. Ualah nou bejuluk you beadek, iling mewari ngejuk ngakuk nemui nyimah ulah nou pandai you nengah you nyappur, nyubadi jejamou, begamiy balak, sakai sambayan."

Terjemahannya:

Tandanya orang Lampung, ada Piil Pesenggiri, ia berjiwa besar, mempunyai malu, menghargai diri. Karena lebih bernama besar dan bergelar. Suka bersaudara, beri memberi terbuka tangan. Karena pandai, ia ramah suka bergaul. Mengolah bersama pekerjaan besar dengan tolong-menolong. (Ariyani, Farida (2015:16).

Keempat konsep yang terkandung dalam Piil Pesenggiri masyarakat Lampung dapat dijelaskan sebagai berikut:

a. Juluk Adek, mengandung arti suka dengan nama baik dan gelar yang terhormat. b. Nemui Nyimah, mengandung arti suka menerima dan memberi dalam suasana suka dan duka.

c. Nengah Nyappur, mengandung arti suka bergaul dan bermusyawarah dalam menyelesaikan suatu masalah.

d. Sakai Sambayan, mengandung arti suka menolong dan bergotong royong dalam hubungan kekerabatan dan ketetanggaan. (Ariyani, Farida (2015:16).

Penelitian tentang Piil Pesenggiri telah banyak dilakukan. Namun demikian penelitian yang berfokus pada kajian Piil Pesenggiri dalam sastra Lampung baru dilakukan Dewi Ratnaningsih dengan judul "Nilai Budaya Lampung (Piil Pesenggiri) dalam Sastra Lisan Pepaccur Masyarakat Lampung Pepadun dalam Prosesi Pengambilan Gelar Adat" (Jurnal Pesona, Vol 5, No 1 2019). Dalam penelitian tersebut diungkap 5 konsep Piil Pesenggiri masyarakat Lampung Abung, seperti Kotabumi Ilir, Blambangan Pagar, Surakarta, Bumi Agung, dan Mulang Maya. Berbeda dengan penelitian tersebut, penelitian yang dilakukan oleh penulis terfokus pada konsep Piil Pesenggiri dalam naskah wawancan yang berkembang pada masyarakat Lampung Saibatin.

Dari latar belakang di atas penulis merumuskan masalah yakni Bagaimana konsepsi Piil Pesenggiri (termasuk di 
Konsep Piil Pesenggiri...

dalamnya konsepsi Bejuluk Buadek, Nengah Nyappur, Nemui Nyimah, dan Sakai Sambayan) direpresentasikan melalui wawancan.

\section{METODE PENELITIAN}

Penelitian ini menggunakan metode kualitatif. Metode kualitatif lebih relevan digunakan dalam mengkaji wawancan yang secara struktur berbentuk tulisan dan ucapan lisan. Menurut Bogdan dan Tailor dalam Moeleong, metode kualitatif merupakan prosedur penelitian yang menghasilkan data deskriptif berupa kata-kata tertulis atau lisan atau dari bentuk tindakan kebijakan (Moeleong, Lexy J. 2002:112).

Dalam mengkaji teks wawancan digunakan pendekatan deskriptif analisis. Pendekatan ini dilakukan dengan cara mendeskripsikan fakta-fakta yang kemudian disusul dengan analisis (Ratna, 2004: 53). Analisis berupa interpretasi atau penafsiran seperti halnya penelitian heurmeuntika, yaitu metode yang disejajarkan dengan interpretasi atau penafsiran terhadap bahan kajian yaitu karya sastra yang merupakan konstruksi makna kompleks yang bermedium bahasa untuk pencapaian makna optimal (Ratna, 2004: 45-46).

Untuk mendapatkan analisis yang lebih dalam penulis juga meneliti konteks dengan metode wawancara dan observasi.
Wawancara dilakukan kepada tokoh-tokoh adat dan masyarakat. Sementara observasi dilakukan dengan metode etnografi. Metode etnografi dilakukan langsung di tengah kehidupan masyarakat dan pemangku adat.

Adapun korpus penelitian adalah wawancan yang dimiliki masyarakat Lampung adat Saibatin. Wilayah penelitian dilakukan di Pekon Banding Agung Kecamatan Talang Padang, Kabupaten Tanggamus dan Desa Baturaja, Kecamatan Way Lima, Kabupaten Pesawaran. Di dua daerah tersebut wawancan masih berkembang hingga saat ini. Sumber data yang diteliti adalah naskah wawancan Bulambanan Jimi Putra dan Willi Yana Sari” (Syafii, 2013) yang terdapat di Talang Padang, "Wawancan Nurdin-Ceri (Pampangan) (Hambala, 2020) serta "Wawancan Sejarah Singkat Way Lima"(Hambala 2003), keduanya dari Way Lima Pesawaran.

\section{HASIL DAN PEMBAHASAN}

Berdasarkan analisis yang dilakukan terhadap wawancan Willi Yana Sari" (Syafii, 2013) yang terdapat di Talang Padang, "Wawancan Nurdin-Ceri (Hambala, 2020) serta "Wawancan Sejarah Singkat Way Lima" (Hambala 2003), ditemukan nilai-nilai budaya Piil Pesenggiri di dalamnya. Konsep piil pesenggiri terkandung secara tersurat dalam wawancan 
Saibatin. Konsep piil pesenggiri meliputi Juluk Adek, Nemui Nyimah, Nengah Nyappur, dan Sakai Sambayan. Konsep tersebut bukan hanya tersurat tetapi juga merepresentasikan budaya masyarakat Lampung Saibatin dalam kehidupan seharihari.

\section{Representasi Juluk Adek}

Konsep Piil Pesenggiri yang pertama adalah juluk adek, atau adok, dalam bahasa Lampung dialek pesisir mengandung arti suka dengan nama baik dan gelar yang terhormat. Dalam masyarakat Lampung Saibatin, nama baik atau gelar merupakan satu aspek utama dalam tatanan sosial. Nama menunjukkan strata sosial seseorang. Adok diberikan saat upacara adat atau perkawinan masyarakat Lampung. Adok terkandung dalam wawancan atau disebutkan setelah pembacaan wawancan. Adok biasanya terdiri dua kata di mana setiap kata menggambarkan makna tertentu. Kata pertama menunjukkan strata sosial dalam Saibatin sedangkan kata kedua menunjukkan identitas sosial yang merepresentasikan diri pengantin.

Ada tujuh tingkatan adok. Tiap adok tersebut memiliki kedudukan yang berbeda sehingga berbeda pula hak dan kewajiban yang melekat padanya. Pemberian adok melalui wawancan merupakan kegiatan pemberian identitas budayanya. Melalui adok tersebut, diletakkan identitas kekerabatan dan kasta tertentu. Menurut Yudiansyah (2018), adok adalah sebutan kehormatan kepada seorang yang telah dewasa dan berumah tangga yang diresmikan melalui upacara adat di hadapan tokoh-tokoh adat maupun kerabatnya. Gelar tersebut dalam adat Lampung sebagai penyimbang (pemimpin). Dapat dikatakan bahwa adok adalah sebutan untuk gelar kebangsawanan masyarakat Lampung.

Pemberian gelar adat diberikan kepada kedua pengantin saat akan melangsungkan pernikahan. Momen pemberian gelar pada saat perkawinan memiliki arti bahwa terdapat perubahan fase dari remaja ke dewasa. Fase saat bujang atau gadis memasuki kehidupan berumah tangga. Oleh karena itu mereka pantas untuk diberi gelar adat sebagai penghormatan dan tanda bahwa mereka sudah berumah tangga. Gelar adat ini diterima dari klan bapak dan dari klan ibu, dilakukan di tempat mempelai pria maupun di tempat mempelai wanita (Effendi, 2009).

Dalam wawancan, penyebutan gelar kehormatan disebutkan dalam bagian pembuka. Dalam pembuka, Penyebutan nama tokoh pemuka adat seperti Dalom pemuka bandakh, khaja mulya, pemuka aparat, dan tamu undangan (ukhawan). Hal itu dapat dilihat dalam kutipan teks wawancan berikut: 
Konsep Piil Pesenggiri...

Tabik pun nabik tabik

Ngalam pukha pu nabakh

Pu jama tutukan ni sai khamik

Dalom pemuka bandakh

Mahap pai daya pun

Tabik pun nabik tabik

Tabik mahap pai juga

Pujama tutukani saikhamik

Bu adok khaja mulya

Khesan juga pai tabik

Pu jama tuwan muda

Mahap pai daya pun

Sai terhormat kepala

Penghulu aparat ni

Ukhawan sai muliya

Wabil khusus ku akhi

Jama sa unyin baya

Minak muakhi unyin ni

Kakhanggom hani tiyan

Adok tuha ni dikiti

Nyambung titah jakhagan

Khaja mulya nitah ni

Ngebaca ko wewancan

Nyebakh ko adok hani

Terjemahan:

Permisi mohon permisi

Hamba mohon maaf
Mari bersama ikut ramai

Dalom pemuka bandakh (pemuka adat)

Mohon maaf dahulu tuan

Permisi mohon maaf

Mohon maaf juga

Bersama ikut yang ramai

Bergelar raja mulia

Begitu juga mohon maaf dulu

Bersama tuan muda

Mohon maaf dulu tuan

Yang terhormat kepala

Penghulu aparatnya

Panggilan yang mulia

Yang paling khusus para saudara

Bersama semua orang di dalam

Sanak saudara semuanya

Mufakat kata mereka

Gelar tuanya di kalian

Nyambung gelar juragan

Raja mulia gelarnya

Membacakan wawancan

Menyebarkan gelar katanya

Adok sendiri secara tersurat ada yang disebutkan di tengah wawancan dan ada pula yang disebutkan setelah pembacaan wawancan. Adok terdiri dari dua kata. Setiap kata menggambarkan makna tertentu. Kata pertama merupakan strata sosial dalam Saibatin sedangkan kata kedua bermakna 
identitas sosial seperti karakter, sifat, atau doa yang merepresentasikan diri pengantin. Strata sosial dalam adok memiliki 7 tingkatan adok yang dikategorikan ke dalam dua kelas yakni Bangsawan (Pandia Pakusakha) dan Punggawa (khakhayakhan). Pandia Pakusakha terdiri dari 5 tingkatan yakni (1) Batin - Batin, Raja - Radin; (2) Radin - Minak; (3) Minak - Enton; (4) Kimas (Tihang, Lidah)- Adi (Mas); (5) Mas (Bangsa, Jaga) - Sinang (Cahya). Sementara Punggawa memiliki 2 tingkatan yakni (6) Layang - Anggin, Muda - Anggin dll; (7) Bunga - Rayi, Morep - Rayi, dll.

Tiap adok tersebut memiliki kedudukan yang berbeda sehingga berbeda pula hak dan kewajiban yang melekat padanya. Kedudukan dari masing-masing gelar mempunyai tugas dan fungsi yang berbeda. Perbedaan itu dapat dilihat dalam acara-acara adat di masyarakat seperti dalam pernikahan. Tentu, seorang yang bergelar khaja tidak boleh dijadikan sebagai tukang atau pekerja kasar. Meskipun pada kenyataanya, bisa saja orang yang bergelar adat tinggi pernah juga disuruh-suruh oleh masyarakat biasa, tetapi memiliki tingkat ekonomi yang lebih tinggi. Hal itu terjadi karena ketidaktahuan masyarakat tentang hak dan kewajiban yang melekat pada diri masyarakat adat Saibatin.

Melalui adok, diharapkan masyarakat dapat menghormati pemimpin dan senantiasa menjunjung tinggi budaya leluhur. Ketujuh gelar adat tersebut tidak bisa dipisah-pisahkan, karena semuanya memiliki keterikatan yang erat hubunganya antar satu tingkatan dengan yang lainnya untuk saling menguatkan dan mengokohkan. Pesan-pesan tersebut juga disampaikan dalam wawancan. Perhatikan kutipan berikut:

\section{Adat budaya tatanan}

Adat lampung khusus ni

Sapa ya bulambanan

Ti sekhbong ko adok ni

Adok anjak tutukan

Bekhulung di lajokh ni

Tabik pun ngalam pukha

Nyalingah pai sunyinni

Ajo adok haga ti baca

Simak kuti puakhi

Terjemahan:

Adat budaya dijaga

Adat Lampung khususnya

Siapa yang berumahtangga

Tolong dipakai adok ini

Adok dari pemimpin adat 
Konsep Piil Pesenggiri...

Atau dalam kutipan:

Minak puakhi unyinni

Kham pakai jama jama

Adok delom hejong ni

Ti ingok ko adokna

Dang lagi ngakhuh gelakh ni

Tanda angkon kham diya

Terjemahan:

Saudara semuanya

Mari gunakan sama-sama

Gelar dalam kedudukannya

Mohon gelar ini diingat

Jangan lagi memanggil namanya

tanda hormat kita ke dia

Dalam wawancan ke-2 yang berjudul

"Wawancan

Nurdin

Ceri

(Pampangan)"yang ditulis 7 November 2020, nama kehormatan juga disebut dengan tegas di awal wawancan. Perhatikan kutipan berikut:

\section{Assalamualaikum}

Pekhwatin Kanan Kikhi

Mahap Sunyin Ni Kaum

Sai Tuha sai Ngukha ni

Terjemahan:

Assalamualaikum

Perwatin (dewan adat) di kanan dan kiri
Mohon maaf kepada semua orang

Yang tua maupun yang muda

Menurut Yudiansyah

(2018)

pemberian adok melalui wawancan merupakan kegiatan pemberian identitas budayanya. Di mana melalui adok tersebut diletakkan identitas kekerabatan dan kasta tertentu. Adok yaitu sebutan kehormatan kepada seorang yang telah dewasa dan berumah tangga yang diresmikan melalui upacara adat dihadapan tokoh-tokoh adat maupun kerabatnya.

\section{Representasi Nemui Nyimah}

Nemui Nyimah mengandung arti suka menerima dan memberi dalam suasana suka dan duka. Dalam wawancan pertama secara gamblang disebutkan istilah nemui nyimah. Perhatikan kutipan wawancan berikut:

Minak muawakhi unyin ni Engok kham sa unyin ya Nemu nyimah muakhi

Sai sanak kitik sai tuha (2013:2)

Terjemahan:

Saudara saudari semuanya Ingat kita semuanya Saling mengasihi sesama saudara Baik yang muda maupun tua 
Nilai-nilai Nemui Nyimah juga ditemukan dalam wawancan "Sejarah Singkat Way Lima" yakni sikap ikhlas masyarakat ketika menyediakan lokasi untuk pembangunan kecamatan baru.

Khepa ki inda-inda

Ikhlas kodo di hati

Masyarakat Batukhaja

Nyedia kon lokasi

(2003:1)

Terjemahan:

bagaimana kira-kira

ikhlaskanlah hati kita

masyarakat baturaja

menyediakan lokasi

Representasi nemui nyimah dalam kehidupan sehari-hari masyarakat Lampung ditunjukkan dalam adat budaya memberi dan menerima seperti budaya memberi makanan kepada tetangga atau sanak saudara sebelum lebaran, acara syukuran, khitan, dll. Konsep nemui nyimah juga diartikan sebagai keramahtamahan. Konsep tersebut sudah terbukti dilakukan oleh masyarakat Lampung melalui sikap keterbukaan terhadap masyarakat pendatang. Di Talang Padang sendiri, terdapat banyak suku selain Lampung seperti Sunda, Jawa, Semendo, dll. Dalam kehidupan sehari-hari mereka berbaur dan saling menerima sehingga sulit ditemukan konflik sosial antar suku atau golongan.

\section{Representasi Nengah Nyappur}

Nengah nyappur berarti suka bergaul dan bermusyawarah dalam menyelesaikan suatu masalah. Dalam wawancan ditunjukkan ada tradisi bermusyawarah. Dalam masyarakat adat lampung. Pergaulan Musyawarah sering dilakukan dalam proses pemberian adok kepada calon pengantin. Musyawarah juga dilakukan dalam penentuan tanggal pernikahan. Seperti dalam wawancan berikut ini:

Khasan laju sai tuha

Ngekhedok khasan jadi

Mupakat hulun tuha

Kapan haga waktu ni

Di tanggal dua dua

Ijab kabul nikah ni

Terjemahan:

Perasaan sudah sampai ke orang tua Punya perasaan sudah jadi

Musyawarah orang tua

Kapan waktunya

pada tanggal dua-dua

Ijab kabul pernikahan

\section{Representasi Sakai Sambayan}


Sakai sambayan mengandung arti suka menolong dan bergotong royong dalam hubungan kekerabatan dan ketetanggaan. (Ariyani, Farida (2015:16). Menurut Sholihin dalam Mardhitara Nanda Aulia (2016) Sakai sambayan adalah nilai dasar filsafat tolong menolong dan gotong royong dalam praktik sosial kehidupan bermasyarakat. Sakai (sasakai) artinya tolong menolong diantara sesama saling silih berganti. Sambayan (sesambay) artinya gotong royong dalam mengerjakan sesuatu yang berat dan besar. Jadi sakai sambaian mencangkup pengertian yang luas yang termasuk di dalam gotong royong dan tolong menolong, memberikan sesuatu kepihak lain baik material, moril, pikiran, dan sebagainya (Sitorus dalam Supriyansyah, 2020:6).

Dalam prinsip piil pesenggiri sakai sambayan, berarti tolong menolong dan gotong royong, yakni memahami makna kebersamaan atau guyub. Sakai sambayan pada hakekatnya adalah menunjukkan rasa partisipasi dan solidaritas yang tinggi terhadap berbagai kegiatan sosial pada umumnya. Sebagai masyarakat Lampung akan merasa kurang terpandang, apabila tidak mampu berpartisipasi dalam suatu kegiatan kemasyarakatan. Perilaku ini menggambarkan sikap toleransi kebersamaan, sehingga seseorang akan memberikan apa saja secara suka rela apabila pemberian tersebut memiliki nilai manfaat bagi orang atau anggota masyarakat lain yang membutuhkan. (T. Dibyo Harsono, 2009).

Dalam wawancan secara tersurat aspek sakai sambayan tidak secara tekstual disebutkan. Namun secara tersirat wawancan memiliki konteks yang cukup erat dengan falsafah sakai sambayan. Di mana di dalamnya terdapat sikap solidaritas terhadap sesama dan mengandung petuahpetuah yang baik tentang kemasyarakatan. Perhatikan kutipan wawancan di bawah ini:

\section{Kantu kham ngemik gawi}

Kham jejama pukhaga

Betik betik pakai ni

Delom segala cakha

(2013:2)

Terjemahan:

Bantu kita bekerja

Kita bersama punya keinginan

Gunakan yang baik-baik

Dalam segala cara

Dalam kutipan tersebut penulis wawancan memberikan pesan kepada masyarakat agar saling membantu dalam bekerja, agar selalu bekerja sama dan menggunakan tingkah laku yang baik dalam berbagai kegiatan. 


\section{SIMPULAN}

Wawancan merupakan salah satu karya sastra yang sampai saat ini masih berkembang pada masyarakat Lampung Saibatin. Sebagai karya sastra wawancan dapat merepresentasikan nilai-nilai budaya yang terkandung dalam masyarakat seharihari, salah satunya falsafah hidup orang Lampung yakni piil pesenggiri. Hasil penelitian menunjukkan bahwa konsep piil pesenggiri terkandung dalam wawancan Saibatin. Konsep piil pesenggiri meliputi Juluk Adek, Nemui Nyimah, Nengah Nyappur, dan Sakai Sambayan. Konsep tersebut bukan hanya tersurat tetapi juga merepresentasikan budaya masyarakat Lampung Saibatin dalam kehidupan seharihari.

Dari hasil penelitian ini penulis sampaikan terima kasih kepada Universitas Teknokrat Indonesia yang telah mendukung dan memfasilitasi kegiatan penelitian skema Penelitian Pengembangan Kapasitas (PPK).

\section{DAFTAR PUSTAKA}

Abdullah. (2008). Kamus Bahasa (Lampung-Indonesa, IndonesiaLampung). Bandarlampung.

Ariyani, Farida, dkk. (2015). Konsepsi Piil Pesenggiri menurut masyarakat adat Lampung Waykanan di Kabupaten Waykanan (Sebuah Pendekatan Discourse Analysis). Bandarlampung: Aura Publishing.
Aulia, Mardhitara Nanda. (2016). Pola Aktivitas Sakai Sambayan dalam Masyarakat Multikultural di Kelurahan Kedamaian Kecamatan Kedamaian. Bandarlampung: Unila. http://digilib.unila.ac.id/21954/

Barker, Chris. (2000). Cultural Studies. Yogyakarta: Kreasi Wacana.

Fakhrurozi, Jafar dan Shely Nasya Putri. (2019). Fungsi Wawancan dalam Upacara Adat Pengantin Lampung Saibatin. Jurnal Salaka: Volume 1 Nomor 2 Tahun 2019. https://journal.unpak.ac.id/index.php/s alaka/article/view/1281.

Hadikusuma, Hilman. (1983). Bahasa Lampung. Lampung: Gunung Pesagi.

Hambala, Saiful. (2003). Wawancan Nurdin-Ceri (Pampangan). Naskah wawancan tidak diterbitkan.

Hambala, Saiful. (2020). Wawancan Sejarah Singkat Way Lima. Naskah wawancan tidak diterbitkan.

Harsono, T. Dibyo. (2009). Masyarakat Adat Lampung Saibatin dalam arus Perkembangan Zaman. (http://wisatadanbudaya.blogspot.co.id /2009/07/masyarakat-adat-lampungSaibatin dalam_24.html di akses pada 20 September 2020)

Koentjaraningrat. (2002). Manusia dan Kebudayaan di Indonesia. Jakarta: Djambatan.

Penyusun, Tim. (2011). Pertumbuhan dan Persebaran Penduduk Indonesia Hasil Sensus Penduduk 2010. Jakarta: Badan Pusat Statistik.

Rahardi, Kunjana R. (2005). Pragmatik: Kesantunan Imperatif Bahasa Indonesia. Jakarta: Erlangga.

Ratnaningsih, Dewi. (2019). Nilai Budaya Lampung (Piil Pesenggiri) dalam 
Konsep Piil Pesenggiri...

Sastra Lisan Pepaccur Masyarakat Lampung Pepadun dalam Prosesi Pengambilan Gelar Adat. Jurnal Pesona, Vol 5, No 12019. https://ejournal.umpri.ac.id/index.php/ pesona/article/view/790

Umar, Rusdi. (1986). Arsitektur Tradisional

Daerah Lampung. Jakarta:

Departemen Pendidikan dan

Kebudayaan, Proyek Inventarisasi dan Dokumentasi Kebudayaan Daerah.

Syafii HR, M. (2013). Wewancan Bulambanan Jimi Putra-Willi Yana Sari. Naskah wawancan tidak diterbitkan.

Supriyansyah. (2020). Remaja dan Kebudayaan dalam Implementasi Falsafah Hidup Sakai Sambayan di Tiyuh Penumangan Kecamatan Tulang Bawang Tengah Kabupaten Tulang Bawang Barat. Bandarlampung: UIN Raden Intan. http://repository.radenintan.ac.id/1245 $0 /$

Yudiansyah, Teguh. (2018). Makna Gelar Adat Lampung Saibatin (Studi di Pekon Kenali Kecamatan Belalau Kabupaten Lampung Barat). Bandarlampung: UIN Raden Intan Lampung.

http://repository.radenintan.ac.id/2931 / 